International Journal of English Literature and Social Sciences
Vol-6, Issue-2; Mar-Apr, 2021

\title{
Measuring competitive intelligence Network and its role on Business Performance
}

\author{
Bayad Jamal Ali ${ }^{1}$, Govand Anwar ${ }^{2}$
}

${ }^{1}$ Business Administration Department, Komar University of Scompetitive intelligence Network nce and Technology, Sulaimani 46001, Kurdistan Region - Iraq

${ }^{2}$ Department of Business Administration, College of Administration and Financial Scompetitive intelligence Network nces, Knowledge University, 44001 Erbil, Kurdistan Region, Iraq

Received: 03 Jan 2021; Received in revised form: 27 Feb 2021; Accepted: 29 Mar 2021; Available online: 26 Apr 2021

C2021 The Author(s). Published by Infogain Publication. This is an open access article under the CC BY license

(https://creativecommons.org/licenses/by/4.0/).

\begin{abstract}
Changes and uncertainties have compelled a dramatic change in organizational fundamentals over the last two decades. Owing to internal and external pressures, businesses have been forced to closely track their environments in order to build awareness of opportunities and obstacles in order to stay competitive. The aim of this study is to look into the role of competitive intelligence in small and medium businesses in Iraq's Kurdistan region making business performance. However, the researchers measured the direct impact on business performance at small and medium businesses using five competitive intelligence dimensions (extensiveness' network, third-party strategy, Homophily, Issue awareness, and promotion effort). Furthermore, the researchers used competitive intelligence as a mediator to quantify its impact on business performance, allowing the analysis to explore the indirect role of competitive intelligence. To investigate the role of competitive intelligence in making business performance at small and medium businesses in Iraq's Kurdistan region, the researchers used hierarchal multiple regression and the Sobel test. However, the researchers measured the direct impact on business performance at small and medium businesses using five competitive intelligence dimensions (extensiveness network, third-party strategy, homophily, issue awareness, and promotion effort). Furthermore, the researchers used competitive intelligence as a mediator to quantify its impact on business performance, allowing the analysis to explore the indirect role of competitive intelligence. Competitive intelligence dimensions (extensiveness network, third-party strategy, homophily, issue awareness, and promotion effort) were used to assess the direct and indirect effect of competitive intelligence on business performance at small and medium businesses.
\end{abstract}

Keywords-extensiveness network, Business Performance, Small and Medium enterprises.

\section{INTRODUCTION}

Knowledge is available for the preparation and execution of business operations. "Intelligence required for the creation of national and theater-level strategy, policy, and military plans and operations" is the definition of strategic intelligence. In other words, strategic intelligence is the data used to create and implement a policy, typically a grand plan or a national strategy, as defined by the government. The justification that determines a strategy, not the plan itself, is referred to as a policy (López-Robles et al. 2018). A strategy helps progress toward goals by suggesting ways to meet and/or orchestrate a large number of variables-variables that are frequently too numerous for the planner to anticipate and comprehend on their own. Dealing with foreign countries necessitates in-

ISSN: 2456-7620

https://dx.doi.org/10.22161/ijels.62.50 depth expertise, which strategic intelligence provides (Anwar, 2017). Without the insights of deep expertise-dependent on detailed knowledge of threats and rewards, enemies and allies in a foreign field - a strategy is nothing more than an abstract idea, or even a flight of fancy (Granados \& Velez-Langs, O2018). The more strategic intelligence there is, the better, which is why the term "strategic intelligence" should not be so ambiguous (Kumar et al. 2020). Since different business organizations are governed by competitive advantage and the struggle for survival as a result of globalization, privatization, and sections of information technology and the digital economy, entail obligations are great at making decisions, so decision-making in business organizations should be based on scompetitive intelligence Network ntific methodology, a large 
number of tools, and a large number of factors. In order to grow Erbil and its organizations (Koriyow \& Karugu, 2018), strategic intelligence and organizational ingenuity are needed to develop strategies for cases of repetition, impasse, and misconceptions in our organizations, as well as to identify a structure to follow up on these only competitive and accessible new horizons for business organizations (Anwar \& Shukur, 2015). Because of modernity, researchers and academics began to understand the importance of strategic intelligence, as well as a number of definitions offered by writers and researchers who rushed to this form of intelligence, as well as diverse views of writers, scholars, and experts on the essence of strategic intelligence (Anwar, 2016). According to a comparative analysis of its dimensions and the various aspects that were based on, strategic intelligence is a job that deals with the business environment and demand, corporate identity and get sources, environmental variables, and social and technological forecasting, in order to achieve lasting and effective, gain expertise, and mental wisdom (Xuefei et al. 2018). It also deftly characterizes leaders with a promising future (prospective, reflection, organization, collaboration, and motivational ability). Because of the structure and process, they employ articles that result in good business intellectual resolutions (Abdullah et al. 2017). Strategic intelligence, according to Ali, (2021), is the informational process by which an organization listens to the situation in order to determine the steps and activities required to achieve its goals. Citing (Anwar \& Balcioglu, 2016), which intelligently describes the characteristics of leaders (prospective, systematic thinking, vision, partnership, ability to motivate employees). The versatility of this type of intelligence drew a lot of attention to this theme (adopted by a variety of countries and government institutions, as well as public and private organizations, corporations, and individuals). She now works with organisations that are addressing new challenges and risks (new mechanisms and strategic techniques to predict and plan for emergencompetitive intelligence Network $s$ before they occur) as a result of witnessing the last decade of the twentieth century and the growth in intelligence requirements and potential (Gatibu \& Kilika, 2017). Strategic intelligence was first used in military operations in the fourth century BC, when it was hired by (Anwar, 2017), one of the world's most prominent military strategists, "so that a wise Commander military dominance could do things beyond the skill of the Ordinary leaders are former information, beyond knowledge outputs of wits with highlighting their value" (Demir, et al. 2020). According to Hameed and Anwar (2018), this form of intelligence is an area with a long history, but it lacks a consistent meaning and agreement. This is not to disparage the work of many of its practitioners; rather, the following points out that, considering the duration and scope of historical experience, there is much more work to be done in terms of exploring the limits and possibilities for this form of intelligence. See (Anwar \& Abd Zebari, 2015) to Central Intelligence Agency (CIA) (Central Intelligence Agency) was the first to use this style of intelligence in the implementation of arms control agreements, and in supplying political decision makers and policy formulation, strategic intelligence, describing Agency Intelligence cycle in the process of information acquisition and transfer, and evaluated and strategize (Anwar \& Ghafoor, 2017). As organizations began to realize the importance of this mode of intelligence and featured many metrics on the evolution of this intelligence, several institutions in Europe and North America began to create strategic intelligence units within organizations to provide insight to policymakers and academic training programmes on smart style intelligence (Kumar et al. 2020). Many businesses are also developing strategic intelligence, which is generated by a group of experts who provide basic advice that serves as the basis for senior management decisions on topics such as Chairperson integration with other organizations and new product development (Anwar \& Surarchith, 2015). The decision-making process is difficult in circumstances where markets are experiencing substantial development in various ways (Andavar \& Ali, 2020). There are new products and other withdrawal and emerging products, as well as an increase in the number of sellers or suppliers, and other factors that affect the decision in terms of products. This is a complex description of time marketing decisions since they are more complicated than any other decision taken by the Administration, and the complexity of this return to a sentence of explanations is largely dependent on the presence of variables (Muñoz-Cañavate \& Hípola, 2017). 


\section{Research Model}

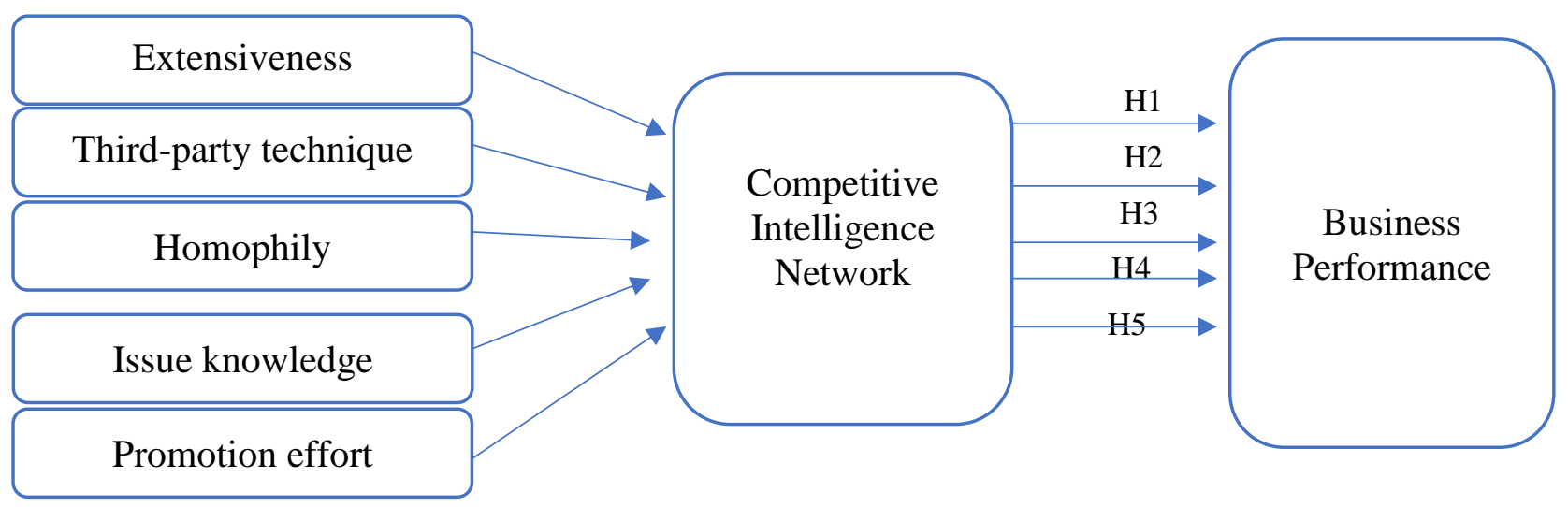

Fig.1: Conceptual Framework

\section{Research Hypotheses:}

H1: Competitive intelligence mediates extensiveness' network and Business performance.

$\mathrm{H} 2$ : Competitive intelligence mediates third-party technique and Business performance.

H3: Competitive intelligence mediates Homophily and Business performance.

H4: Competitive intelligence mediates Issue knowledge and Business performance.

H5: Competitive intelligence mediates promotion effort and Business performance.

\section{THEORETICAL BACKGROUND}

Because of modernity, researchers and academics began to understand the importance of strategic intelligence, as well as a number of definitions offered by writers and researchers who rushed to this form of intelligence, as well as diverse views of writers, scholars, and experts on the essence of strategic intelligence (Anwar, 2016). According to a comparative analysis of its dimensions and the various aspects that were based on, strategic intelligence is a job that deals with the business environment and demand, corporate identity and get sources, environmental variables, and social and technological forecasting, in order to achieve lasting and effective, gain expertise, and mental wisdom (Anwar, 2017). It also deftly characterizes leaders with a promising future (prospective, reflection, organization, collaboration, and motivational ability). Because of the structure and process, they employ articles that result in good business intellectual resolutions (Abdullah et al. 2017). Strategic intelligence, according to Yun et al. (2020), is the informational process by which an organization listens to the situation in order to determine the steps and activities required to achieve its goals. Citing (Anwar \& Balcioglu, 2016), which intelligently describes the characteristics of leaders (prospective, systematic thinking, vision, partnership, ability to motivate employees). The versatility of this type of intelligence drew a lot of attention to this theme (adopted by a variety of countries and government institutions, as well as public and private organizations, corporations, and individuals). She now works with organisations that are addressing new challenges and risks (new mechanisms and strategic techniques to predict and plan for emergencompetitive intelligence Network s before they occur) as a result of witnessing the last decade of the twentieth century and the growth in intelligence requirements and potential (Ali, 2021). Strategic intelligence was first used in military operations in the fourth century BC, when it was hired by (Anwar, 2017), one of the world's most prominent military strategists, "so that a wise Commander military dominance could do things beyond the skill of the Ordinary leaders are former information, beyond knowledge outputs of wits with highlighting their value" (Mehl \& Le Bon, 2019). According to Hameed and Anwar (2018), this form of intelligence is an area with a long history, but it lacks a consistent meaning and agreement. This is not to disparage the work of many of its practitioners; rather, the following points out that, considering the duration and scope of historical experience, there is much more work to be done in terms of exploring the limits and possibilities for this form of intelligence. See (Anwar, 2016) to Central Intelligence Agency (CIA) (Central Intelligence Agency) was the first to use this style of intelligence in the implementation of arms control agreements, and in supplying political decision makers and policy formulation, strategic intelligence, describing 
Agency Intelligence cycle in the process of information acquisition and transfer, and evaluated and strategize (Anwar \& Ghafoor, 2017). As organizations began to realize the importance of this mode of intelligence and featured many metrics on the evolution of this intelligence, several institutions in Europe and North America began to create strategic intelligence units within organizations to provide insight to policymakers and academic training programmes on smart style intelligence (Caseiro \& Coelho, 2019). Many businesses are also developing strategic intelligence, which is generated by a group of experts who provide basic advice that serves as the basis for senior management decisions on topics such as Chairperson integration with other organizations and new product development (Ali, 2020). The decision-making process is difficult in circumstances where markets are experiencing substantial development in various ways. There are new products and other withdrawal and emerging products, as well as an increase in the number of sellers or suppliers, and other factors that affect the decision in terms of products. This is a complex description of time marketing decisions since they are more complicated than any other decision taken by the Administration, and the complexity of this return to a sentence of explanations is largely dependent on the presence of variables (Naeini et al. 2019).

The difficulty in estimating relationships between various variables that are susceptible to shifting and switching over different time periods is usually limited to the dispersion of different sources of data and expertise, which often contain a high degree of risk and information for decision making (Anwar \& Qadir, 2017). External variables can be forecasted even if the magnitude levels are high, since most categories in a single project cannot be expected. Finance Department cannot complete budget and production without expected revenue numbers, production table, or even making decisions unless marketing department sales figures are given (Anwar $\&$ Climis, 2017). There is a fact that must be understood, and that all administrative activities per initiative that are responsible for adhering to reduce Melisma, or marketing process, are responsible for the reduction and access setup bilaterally. Perhaps the problem with marketing is that decisions are seldom taken without the involvement of others (Saddhono et al. 2019). The information about this customer, in particular, Dodd is a marketing decision maker on the one hand, and marketing decision makers are recognizing this on the other. Another issue is that obtaining the necessary data and information is neither feasible nor convenient, particularly if it comes at a high cost in terms of both time and money. The collection of appropriate data and content information is important so that the outcome benefits the majority of parties, rather than teaser decisions about the consumer and how to satisfy his wants and wishes, though the decision would take antitrust regulators, stock and bond holders, and other considerations into account (Espinet \& Alsina, 2017). Many multifaceted concepts are clear as a result of the various entrances to discuss the strategic decision by the book Department and researchers agreeing with many authors, like (Fanbing, 2017). Using market portals and the strategic judgment theory, also known as strategic decisions, as such decisions that dealt with its scale, complexity, and multidimensional nature. A selection of strategic alternatives that represents the best way to achieve the organization's objectives is won by fateful decisions involving areas related to growth and organization creation (Anwar \& Louis, 2017). Strategic decisions, according to Anwar \& Shukur (2015), are those that take into account internal and external problems and opportunities in order to promote long-term growth, which means strategic decisions that have a broad impact on the organization (Ali \& Anwar, 2021 ). The strategic decision affects all aspects of the organization, not just one, and it has a long-term rather than a short-term effect. It also reflects the President's commitment to achieve the organization's main goals (Zhiyin \& Jiakun, 2017). And when it comes to strategic decisions that affect the organization's future in depth by ensuring those capacities to respond to environmental requirements, (Kori et al. 2020) reacts in an understandable manner with (Mintzberg). Either (Drucker) explains the strategic decision that the Administration should make in order to achieve the Organization's goals in a competitive world where other people's activities are a factor (Abdullah \& Anwar,2021). Strategic decisions, as Itani et al. (2017) point out, are rare special resolutions that require long-term liabilities and long responsibilities, as well as a high degree of importance, so any error may expose the Organization to a variety of risks. While he sees (Bheekharry, 2020) a strategic decision situation emerging between the strengths and vulnerabilities of the Organization's internal and external risks prospects, he sees (Tarek et al. 2019) a strategic decision situation emerging between the strengths and vulnerabilities of the Organization's internal and external risks prospects. A resolution dealing with long-term variables related to the Organization's performance, or the major axial impact in preserving the effectiveness of current and represents a particular form of administrative decision taken in the face of uncertainty, according to Prabhu et al. (2020). And discovering (Anwar \& Surarchith, 2015) that strategic decisions include researching complex problems that require research, are relatively stable, and deal with the Organization's priorities, as their importance and priority vary by administrative levels. Supreme strategic decisions, as well as the emotionally exhausting and challenging use of analysts and consultants, as well as the involvement of all parties involved in the problem to ensure sound decisions and market players And understood (Zhao et al. 2019) strategic decisions as those that characterize the Organization and direction of the 
General Foundation biography in terms of the expected and unexpected factors that emerge in the world, and in the end form the Organization's actual objectives, and help draw the map, from which the Organization of function, and to exercise (López-Robles et al. 2020). As shown in the following chronological list of strategic marketing concepts, many of the meanings offered by writers and scholars on the subject of business performance were personal views on both the nature study and his approach to his topic. In the present period, extraordinary decisions are made with a high degree of importance in terms of future periods, which are based on the organization's intent by understanding how decision-making processes work, as well as creative abilities to convince internal and external environment changes (Shaitura et al. 2018). Also, (Zhiyin \& Jiakun, 2017), because decisions made in the face of danger and a lack of knowledge are often erroneous, because they are made with inadequate information, and also because the law is uncertain in the future, such decisions require distinct capabilities and are more likely to be made with incomplete information. In the light of a larger picture of the company's prospects.

Decisions about the entity's management and future, as well as its climate, whether this sort of comparatively stable longterm, significant commitments or funds for deployment, and making such decisions at the top of the corporate pyramid (Ali \& Anwar, 2021 ). Those decisions are about Parallels, while others are about the Organization's long-term future (Anwar $\&$ Louis, 2017). Decisions on the Organization's targets and strategies for achieving them, as well as predicting and tracking external developments, searching for ways to improve performance, and determining the resources needed to achieve objectives, as well as resource allocation and usage regulations and top management knowledge (Anwar \& Qadir, 2017). Acquisitions and mergers, joint ventures and strategic alliances, and locating a new financing and reorganization location, among other items, all have an effect on the Company and the outcomes of these decisions. The organization's senior management, headed by the Executive Director or Manager of the company, makes critical and strategic decisions (Anwar, 2017). Decisions on the key options for enterprise growth objectives and orientations on the form of output or operation to which you want enterprise access take longer and require higher operating standards than previous resolutions (Espinet \& Alsina, 2017). Decisions about the organization's integration, complexity, strategic role, and products and services provided (Anwar \& Climis, 2017) are examples of decisions that form the organization's trajectory and have a large impact on the organizational unit. Important actions that have shaped the organization's longterm profile and defined the organization's long-term path (Anwar, 2016). Special resolutions often include long-term commitments and acquisitions, but any error that could expose the Organization to several threats should be avoided (Hameed \& Anwar, 2018). Decisions made now with a high degree of urgency, in terms of their effect on the Bank in the future stages, and focused on achieving the Bank's goal by learning how to streamline the decision-making process during which, and the professional advocate for briefing the internal environment variables (Ali, 2020). If this industry requires mental flexibility and own creative skills to identify the greatest percentage of variables influencing the manufacturing process as a result of unexpected threats, and potentially influential environmental opportunities arise in the future, and the results of these decisions have long-term success for the Organization (Anwar \& Balcioglu, 2016). Non-programmed decisions necessitate long-term goals and plans, as well as dealing with emerging problems that demand hard and strategic thinking from senior management (Caseiro \& Coelho, 2019). The Organization's true goals are decisions that determine the organization and direction of the General Foundation course in light of expected and uncertain factors in the world. These choices aid in the creation of a map, the distribution of resources, and the assessment of the Organization's viability (Abdullah et al. 2017). The organization's long-term objectives, as determined by a longrange strategy and a medium-range plan (Anwar, 2017). Before the onset of crises, non-traditional decisions involving several dimensions and planning issues of great complexity and depth, which are impossible to address with an instant decision, are made to determine how to respond to these problems (Anwar \& Balcioglu, 2016). Decisions that consider opportunities, external threats, and internal capital in order to enhance the Organization's long-term success so that it has a broad impact and lasts too long (Hameed \& Anwar, 2018). The resolution of value is based on foreseeing and anticipating the Organization's future and projecting their needs to enable both data and administrative, scompetitive intelligence Network ntific, and technical capacities, and it necessitates an efficompetitive intelligence Network nt professional and managerial leadership that is well aware of what will work and perspective in the future and decided with all factors surrounding it. To assist the company in adjusting to the external environment through analysis and notification, in order to achieve a wide range of development and desired outcomes (Anwar \& Ghafoor, 2017). Senior management allocates resources to adapt to the organization's environment and competing agendas in order to ensure the organization's long-term survival (Demir, et al. 2020). (Ali, 2021) Represents the organization's fundamental direction and makes job decisions based on methodology and simulation of trends and predicted external and internal dynamics. The organization's policy option, which determines the long-term pattern because it deals with non-traditional formulas and potential employment, is an example of higher-level strategic 
choices (Othman \& Abdullah, 2016). The decision of great importance based on predictability and Orientalism to the Organization's future and predicting their requirements to unlock all the data and administrative, scompetitive intelligence Network ntific, and technological tools, and requires an efficompetitive intelligence Network nt professional and managerial leadership is fully aware of what will function and intuition in the future and measured for all variables surrounding it, and requires an efficompetitive intelligence Network nt professional and managerial leadership is fully aware of what will function and intuition in the future and measured for all variables surrounding it, and requires an efficompetitive intelligence Network nt professional and managerial leadership is fully aware of what will function and intuition in To assist the company in adjusting to the external environment through analysis and notification, in order to achieve a wide range of development and desired outcomes (Anwar \& Shukur, 2015). Strategic decisions are (special decisions taken by senior management to achieve long-term sustainability and built on the basis of foreseeing and vision for the Organization's future leaders and by forecasting, visualizing, and monitoring global trends in order to capture opportunities and reduce the consequences of risks, according to the marketing analyst (Anwar \& Qadir, 2017).

\section{METHODOLOGY}

The research was conducted in Erbil's small and medium enterprises. The research looked at the perspective of competitive intelligence Network in the SMEs, specifically in private hospitals. To quantify SMEss' Business performance, the researchers used five competitive intelligence Network metrics, such as extensiveness network, Third-party technique, and Business performance, Homophily, degree of change, and promotion effort. Furthermore, the researcher used competitive intelligence as a mediator for all five independent variables to assess business performance in the SMEs. To find a competitive intelligence Network perspective in the SMEs field, the researchers used a quantitative analysis approach. A total of 130 administrative staff members from private hospitals were given the questionnaire at random. The participants in this study were 112 people from various private hospitals in Iraq's Kurdistan province. The questionnaire contained 59 things ranging from 1=Strongly Disagree, 2= Disagree, $3=$ Neutral, 4= Agree, and $5=$ Strongly Agree, all of which were measured using a fivepoint Likert scale ranging from 1=Strongly Disagree, $2=$ Disagree, 3= Neutral, 4= Agree, and 5= Strongly Agree.

\section{ANALYSIS AND RESULTS}

Table 1-KMO and Bartlett Sphericity Test of Self-rating Items

\begin{tabular}{|c|c|c|c|c|c|}
\hline \multirow[t]{2}{*}{ Factors } & \multirow{2}{*}{$\begin{array}{l}\mathrm{N} \text { of } \\
\text { items }\end{array}$} & \multirow[t]{2}{*}{$\mathrm{n}$} & \multirow[t]{2}{*}{ KMO } & \multicolumn{2}{|c|}{ Bartlett test } \\
\hline & & & & Chi-Square & Sig \\
\hline extensiveness network & 10 & 124 & \multirow{7}{*}{.772} & \multirow{7}{*}{1871.3} & \multirow{7}{*}{.000} \\
\hline Third-party technique & 9 & 124 & & & \\
\hline Homophily & 11 & 124 & & & \\
\hline Issue knowledge & 10 & 124 & & & \\
\hline Promotion effort & 9 & 124 & & & \\
\hline Competitive Intelligence Embeddedness & 11 & 124 & & & \\
\hline Business performance & 10 & 124 & & & \\
\hline
\end{tabular}

As we can see in table (1), the result of KMO for all five independent variables (extensiveness network, duration of the change, change assessment, degree of change, and Issue knowledge), and Business performance as dependent variable also competitive intelligence Network as mediator factor; is .751 which is higher than .001 this indicates that the sample size used for the current study was more than adequate. Furthermore, the result of Chi-Square is 2155.2 with the significant level .000 . 
Table 2: Reliability analysis

\begin{tabular}{|l|c|c|c|}
\hline Factors & N of items & $\mathrm{n}$ & Cronbach's Alpha \\
\hline extensiveness network & 10 & 124 & .791 \\
\hline Third-party technique & 9 & 124 & .737 \\
\hline Homophily & 11 & 124 & .729 \\
\hline Issue knowledge & 10 & 124 & .787 \\
\hline Promotion effort & 9 & 124 & .776 \\
\hline Competitive Intelligence Embeddedness & 11 & 124 & .755 \\
\hline Business performance & 10 & 124 & \\
\hline
\end{tabular}

As shown in table (2), the reliability analysis for 59 items was used to determine the impact of five independent variables (extensiveness network, Third-party technique, Homophily, degree of change, and Issue knowledge), as well as a dependent variable (Business performance) and a mediator factor (competitive intelligence Network ). 8 items for Extensiveness network, 9 items for Duration of Change, 8 items for Change Assessment, 8 items for Degree of Change, 9 items for Issue knowledge, 9 items for Firm Performance, and 8 items for Competitive intelligence Network were distributed among the 59 questions. The researchers used reliability analysis to determine the reliability of each factor, with the following results: In terms of extensiveness network, the Alpha was discovered to be. The Alpha for Duration of the Change was found to be 733 with a sample size of 112 for 8 questions, indicating that all 8 questions used to test Extensiveness network were accurate for the current analysis. The Alpha for Change Assessment was found to be 729 with a sample size of 112 for 9 questions, indicating that all 9 questions used to test Duration of Change were accurate for the current analysis. The Alpha for Issue Information was found to be 768 with a sample size of 112 for 8 questions, indicating that all 8 questions used to test Change Assessment were accurate for the current analysis. The Alpha for Promotion effort was found to be 791 with a sample size of 112 for 9 questions, indicating that all 9 questions used to test Issue information were accurate for the current analysis. The Alpha for Firm Performance was found to be 788 with a sample size of 112 for 9 questions, indicating that all 9 questions used to test Promotion effort were accurate for the current analysis. The Alpha for Firm Performance was found to be. 739 with a sample size of 112 for 9 questions, indicating that all 9 questions used to measure Firm Performance were accurate for the current study. For Competitive intelligence Network, the Alpha was found to be. 739 with a sample size of 112 for 8 questions, indicating that all 8 questions used to measure Competitive intelligence Network were reliable for the current study.

Table 3: Correlation Analysis

\begin{tabular}{|c|c|c|c|c|c|c|c|c|}
\hline \multicolumn{9}{|c|}{ Correlations } \\
\hline & & Market & Competitor & Customer & Partner & Technical & $\begin{array}{l}\text { Competitive } \\
\text { Intelligence } \\
\text { Network }\end{array}$ & $\mathrm{BP}$ \\
\hline \multirow[t]{3}{*}{$\begin{array}{l}\text { extensiveness } \\
\text { network }\end{array}$} & $\begin{array}{l}\text { Pearson } \\
\text { Correlation }\end{array}$ & 1 & & & & & & \\
\hline & $\begin{array}{l}\text { Sig. (2- } \\
\text { tailed) }\end{array}$ & & & & & & & \\
\hline & $\mathrm{N}$ & 124 & & & & & & \\
\hline \multirow[t]{3}{*}{$\begin{array}{l}\text { Third-party } \\
\text { technique }\end{array}$} & $\begin{array}{l}\text { Pearson } \\
\text { Correlation }\end{array}$ & $.601^{* *}$ & 1 & & & & & \\
\hline & $\begin{array}{l}\text { Sig. (2- } \\
\text { tailed) }\end{array}$ & .002 & & & & & & \\
\hline & $\mathrm{N}$ & 124 & 124 & & & & & \\
\hline
\end{tabular}




\begin{tabular}{|c|c|c|c|c|c|c|c|c|}
\hline \multirow[t]{3}{*}{ Homophily } & $\begin{array}{l}\text { Pearson } \\
\text { Correlation }\end{array}$ & $.547^{* *}$ & $.591^{* *}$ & 1 & & & & \\
\hline & $\begin{array}{l}\text { Sig. (2- } \\
\text { tailed) }\end{array}$ & .000 & .000 & & & & & \\
\hline & $\mathrm{N}$ & 124 & 124 & 124 & & & & \\
\hline \multirow[t]{3}{*}{$\begin{array}{l}\text { Issue } \\
\text { knowledge }\end{array}$} & $\begin{array}{l}\text { Pearson } \\
\text { Correlation }\end{array}$ & $.573^{* *}$ & $.609^{* *}$ & $.618^{* *}$ & 1 & & & \\
\hline & $\begin{array}{l}\text { Sig. (2- } \\
\text { tailed) }\end{array}$ & .000 & .001 & .000 & & & & \\
\hline & $\mathrm{N}$ & 124 & 124 & 124 & 124 & & & \\
\hline \multirow[t]{3}{*}{$\begin{array}{l}\text { Promotion } \\
\text { effort }\end{array}$} & $\begin{array}{l}\text { Pearson } \\
\text { Correlation }\end{array}$ & $.587^{* *}$ & $.512^{* *}$ & $.493^{* *}$ & $.482^{* *}$ & 1 & & \\
\hline & $\begin{array}{l}\text { Sig. (2- } \\
\text { tailed) }\end{array}$ & .000 & .000 & .000 & .000 & & & \\
\hline & $\mathrm{N}$ & 124 & 124 & 124 & 124 & 124 & & \\
\hline \multirow{3}{*}{$\begin{array}{l}\text { Competitive } \\
\text { Intelligence } \\
\text { Embeddedness }\end{array}$} & $\begin{array}{l}\text { Pearson } \\
\text { Correlation }\end{array}$ & $.631^{* *}$ & $.667^{* *}$ & $.597^{* *}$ & $.614^{* *}$ & $.632^{* *}$ & 1 & \\
\hline & $\begin{array}{l}\text { Sig. (2- } \\
\text { tailed) }\end{array}$ & .000 & .000 & .000 & .000 & .000 & & \\
\hline & $\mathrm{N}$ & 124 & 124 & 124 & 124 & 124 & 124 & \\
\hline \multirow[t]{3}{*}{$\begin{array}{l}\text { Business } \\
\text { performance }\end{array}$} & $\begin{array}{l}\text { Pearson } \\
\text { Correlation }\end{array}$ & $.637^{* *}$ & $.648^{* *}$ & $.536^{* *}$ & $.691^{*}$ & $.644^{* *}$ & $.663^{* *}$ & 1 \\
\hline & $\begin{array}{l}\text { Sig. (2- } \\
\text { tailed) }\end{array}$ & .000 & .000 & .000 & .000 & .000 & & \\
\hline & $\mathrm{N}$ & 124 & 124 & 124 & 124 & 124 & 124 & 124 \\
\hline
\end{tabular}

The association analysis between extensiveness network, length of the change, Homophily, degree of change, and Issue knowledge) and Business performance as dependent variables, as well as competitive intelligence Network as a mediator factor, can be seen in table (3). The value of Pearson correlation $\left(\mathrm{r}=.599^{* *}, \mathrm{p} 0.01\right)$ between extensiveness network and business performance was discovered. The Pearson correlation value ( $\left.r=.602^{* *}, \mathrm{p} 0.01\right)$ between the length of the transition and Business performance suggested that there is a positive and clear correlation between extensiveness network and Business performance. The significance of Pearson correlation $\left(\mathrm{r}=.617^{* *}, \mathrm{p} 0.01\right)$ between Homophily and
Business performance suggested that there is a positive and clear correlation between length of the change and Business performance. The importance of Pearson correlation $\left(\mathrm{r}=.697^{* *}, \mathrm{p} 0.01\right)$ between Issue awareness and Business performance suggested that there is a positive and clear correlation between Homophily and Business performance. The importance of Pearson correlation ( $\mathrm{r}=.501 * *, \mathrm{p} 0.01)$ between promotion effort and Business performance suggested that there is a positive and clear correlation between Issue awareness and Business performance. This showed that promotion initiative and business performance have a constructive and close relationship. 
Testing Research Hypotheses

H1: Competitive intelligence mediates extensiveness' network and Business performance.

Table 4-Hierarchal Multiple Regression

\begin{tabular}{|c|c|c|c|c|c|c|}
\hline \multicolumn{7}{|c|}{ Coefficompetitive intelligence Network nts } \\
\hline \multirow{2}{*}{\multicolumn{2}{|c|}{ Model }} & \multicolumn{2}{|c|}{$\begin{array}{c}\text { Unstandardized } \\
\text { Coefficompetitive } \\
\text { intelligence Network nts }\end{array}$} & \multirow{2}{*}{$\begin{array}{c}\text { Standardized } \\
\text { Coefficompetitive } \\
\text { intelligence } \\
\text { Network nts } \\
\text { Beta }\end{array}$} & \multirow[t]{2}{*}{$\mathrm{t}$} & \multirow[t]{2}{*}{ Sig. } \\
\hline & & B & Std. Error & & & \\
\hline \multirow[t]{2}{*}{1} & (Constant) & 1.007 & .121 & & 3.528 & .000 \\
\hline & extensiveness network & .602 & .027 & .606 & 2.641 & .000 \\
\hline \multirow[t]{3}{*}{2} & (Constant) & 1.114 & .123 & & 2.251 & .000 \\
\hline & extensiveness network & .611 & .041 & .617 & 1.258 & .001 \\
\hline & $\begin{array}{l}\text { Competitive Intelligence } \\
\text { Network }\end{array}$ & .609 & .025 & .614 & 3.524 & .000 \\
\hline
\end{tabular}

A hierarchal multiple regression analysis was used to investigate the first research hypothesis, which claimed that competitive intelligence mediates marketing intelligence and business performance (Table 4 ). The value of $\mathrm{B}=.602$, the value of Beta $=.606$, and the P-value $=.000$ for model (1), the direct relationship between marketing intelligence and business performance, showed that there is a strong and optimistic relationship between marketing intelligence and business performance. Model (2), which used multiple regression analysis to discover both marketing intelligence as an independent factor and competitive intelligence as a mediator factor with business performance as a dependent factor, revealed that the value of $\mathrm{B}=.611$, the value of Beta $=.617$ with P-value.001 as an indirect relationship between marketing intelligence and business performance. The results showed that marketing intelligence and business performance have a positive and significant direct and indirect relationship, and that competitive intelligence plays a positive and significant mediating function between marketing intelligence and business performance.

Table 5: Sobel Test

\begin{tabular}{|c|c|c|c|c|c|}
\hline & Input: & & Test statistic: & Std. Error: & $p$-value: \\
\hline$a$ & .611 & Sobel test: & 12.71231682 & 0.02927075 & 0.000 \\
\hline$b$ & .609 & Aroian test: & 12.70452973 & 0.02928869 & 0.000 \\
\hline$s_{\mathrm{a}}$ & .041 & Goodman test: & 12.72011826 & 0.02925279 & 0.000 \\
\hline$s_{\mathrm{b}}$ & .025 & Reset all & \multicolumn{3}{|c|}{ Calculate } \\
\hline
\end{tabular}

P-value is significant at level 0.005

Table (5), illustrates the findings of Sobel test to find the mediation analysis, the result demonstrates the direct relationship between extensiveness' network and Business performance, $\mathrm{P}$-value $=.000$ this indicated that there is a significant and positive direct relationship between extensiveness' network and Business performance. Furthermore, P-value is .000 as indirect relationship between extensiveness' network and Business performance. Moreover, the results proved that there is a positive and significant direct and indirect relationship between extensiveness' network and Business performance, moreover competitive intelligence has a positive and significant mediating role between extensiveness' network and Business performance.

$\mathrm{H} 2$ : Competitive intelligence mediates third-party technique and Business performance. 
Table 6: Hierarchal Multiple Regression

\begin{tabular}{|c|c|c|c|c|c|c|}
\hline \multicolumn{7}{|c|}{ Coefficompetitive intelligence Network nts } \\
\hline \multirow{2}{*}{\multicolumn{2}{|c|}{ Model }} & \multicolumn{2}{|c|}{$\begin{array}{c}\text { Unstandardized } \\
\text { Coefficompetitive intelligence } \\
\text { Network nts }\end{array}$} & \multirow{2}{*}{$\begin{array}{c}\text { Standardized } \\
\text { Coefficompetitive } \\
\text { intelligence } \\
\text { Network nts } \\
\text { Beta }\end{array}$} & \multirow[t]{2}{*}{$\mathrm{t}$} & \multirow[t]{2}{*}{ Sig. } \\
\hline & & $\mathrm{B}$ & Std. Error & & & \\
\hline \multirow[t]{2}{*}{1} & (Constant) & 1.921 & .141 & & 4.252 & .000 \\
\hline & $\begin{array}{l}\text { Third-party } \\
\text { technique }\end{array}$ & .671 & .043 & .679 & 2.521 & .000 \\
\hline \multirow[t]{3}{*}{2} & (Constant) & 1.321 & .114 & & 2.317 & .000 \\
\hline & $\begin{array}{l}\text { Third-party } \\
\text { technique }\end{array}$ & 677 & .072 & .681 & 1.339 & .000 \\
\hline & $\begin{array}{l}\text { Competitive } \\
\text { Intelligence } \\
\text { Network }\end{array}$ & .639 & .031 & .643 & 2.741 & .000 \\
\hline
\end{tabular}

Table (6), demonstrates a hierarchal multiple regression analysis to investigate second research hypothesis which stated that competitive intelligence mediates third-party technique and Business performance. Concerning model (1) the direct relationship between third-party technique and Business performance, the value of $\mathrm{B}=.671$, the value of Beta $=.679$ with $\mathrm{P}$-value $=.000$ this indicated that there is a significant and positive relationship between third-party technique and Business performance. As for model (2) which applied multiple regression analysis to find both third-party technique as independent factor and Competitive intelligence as a mediator factor with Business performance as dependent factor, the findings showed that the value of $\mathrm{B}=.677$, the value of Beta $=.681$ with P-value .001 as indirect relationship between third-party technique and Business performance, on the other hand the value of $\mathrm{B}=.639$, the value of Beta $=.643$ with P-value .000 as mediation between Competitive intelligence and Business performance. The findings proved that there is a positive and significant direct and indirect relationship between third-party technique and Business performance, moreover Competitive intelligence has a positive and significant mediating role between third-party technique and Business performance.

Table 7: Sobel Test

\begin{tabular}{|c|c|c|c|c|c|}
\hline & Input: & & Test statistic: & Std. Error: & $p$-value: \\
\hline$a$ & .677 & Sobel test: & 8.55476351 & 0.05056867 & 0.000 \\
\hline$b$ & .639 & Aroian test: & 8.54644263 & 0.0506179 & 0.001 \\
\hline$s_{\mathrm{a}}$ & .072 & Goodman test: & 8.56310874 & 0.05051939 & 0.002 \\
\hline & .031 & Reset all & \multicolumn{3}{|c|}{ Calculate } \\
\hline
\end{tabular}

P-value is significant at level 0.005

Table (7), illustrates the findings of Sobel test to find the mediation analysis, the result demonstrates the direct relationship between third-party technique and Business performance, P-value $=.000$ this indicated that there is a significant and positive direct relationship between third-party technique and Business performance. Furthermore, $\mathrm{P}$-value is
.001 as indirect relationship between third-party technique and Business performance. Moreover, the results proved that there is a positive and significant direct and indirect relationship between third-party technique and Business performance, moreover Competitive intelligence has a positive and 
significant mediating role between third-party technique and Business performance.
H3: Competitive intelligence mediates Homophily and Business performance.

Table 8: Hierarchal Multiple Regression

\begin{tabular}{|c|c|c|c|c|c|c|}
\hline \multicolumn{7}{|c|}{ Coefficompetitive intelligence Network nts } \\
\hline \multirow{2}{*}{\multicolumn{2}{|c|}{ Model }} & \multicolumn{2}{|c|}{$\begin{array}{c}\text { Unstandardized } \\
\text { Coefficompetitive intelligence } \\
\text { Network nts }\end{array}$} & \multirow{2}{*}{$\begin{array}{c}\text { Standardized } \\
\text { Coefficompetitive } \\
\text { intelligence } \\
\text { Network nts } \\
\text { Beta }\end{array}$} & \multirow[t]{2}{*}{$\mathrm{t}$} & \multirow[t]{2}{*}{ Sig. } \\
\hline & & $\mathrm{B}$ & Std. Error & & & \\
\hline \multirow[t]{2}{*}{1} & (Constant) & 1.714 & .274 & & 1.251 & .000 \\
\hline & Homophily & .592 & .073 & .597 & 2.599 & .000 \\
\hline \multirow[t]{3}{*}{2} & (Constant) & 1.441 & .127 & & 2.993 & .000 \\
\hline & Homophily & .528 & .092 & .531 & 1.7125 & .000 \\
\hline & $\begin{array}{l}\text { Competitive } \\
\text { intelligence } \\
\text { network }\end{array}$ & .607 & .052 & .611 & 1.528 & .000 \\
\hline
\end{tabular}

Table (8), demonstrates a hierarchal multiple regression analysis to investigate third research hypothesis which stated that Competitive intelligence mediates change assessment and Business performance. Concerning model (1) the direct relationship between change assessment and Business performance, the value of $\mathrm{B}=.611$, the value of Beta $=.617$ with $\mathrm{P}$-value $=.000$ this indicated that there is a significant and positive relationship between change assessment and Business performance. As for model (2) which applied multiple regression analysis to find both dur change assessment as independent factor and Competitive intelligence as a mediator factor with Business performance as dependent factor, the findings showed that the value of $\mathrm{B}=.622$, the value of Beta $=$ .629 with P-value .001 as indirect relationship between change assessment and Business performance, on the other hand the value of $\mathrm{B}=.633$, the value of Beta $=.639$ with $\mathrm{P}$-value .000 as mediation between Competitive intelligence and Business performance. The findings proved that there is a positive and significant direct and indirect relationship between change assessment and Business performance, moreover Competitive intelligence has a positive and significant mediating role between change assessment and Business performance.

Table 9: Sobel Test

\begin{tabular}{|c|c|c|c|c|c|}
\hline & Input: & & Test statistic: & Std. Error: & $p$-value: \\
\hline$a$ & .528 & Sobel test: & 5.15031023 & 0.06222848 & 0.001 \\
\hline$b$ & .607 & Aroian test: & 5.13515762 & 0.06241211 & 0.000 \\
\hline$s_{\mathrm{a}}$ & .092 & Goodman test: & 5.16559777 & 0.06204432 & 0.002 \\
\hline$s_{\mathrm{b}}$ & .052 & Reset all & \multicolumn{3}{|c|}{ Calculate } \\
\hline
\end{tabular}

P-value is significant at level 0.005

Table (9), illustrates the findings of Sobel test to find the mediation analysis, the result demonstrates the direct relationship between change assessment and Business performance, P-value $=.000$ this indicated that there is a significant and positive direct relationship between change assessment and Business performance. Furthermore, P-value is .000 as indirect relationship between change assessment and Business performance. Moreover, the results proved that there 
is a positive and significant direct and indirect relationship between change assessment and Business performance, moreover Competitive intelligence has a positive and significant mediating role between change assessment and Business performance.
H4: Competitive intelligence mediates Issue knowledge and Business performance.

Table 10: Hierarchal Multiple Regression

\begin{tabular}{|c|c|c|c|c|c|c|}
\hline \multicolumn{7}{|c|}{ Coefficompetitive intelligence Network nts } \\
\hline \multirow{2}{*}{\multicolumn{2}{|c|}{ Model }} & \multicolumn{2}{|c|}{$\begin{array}{c}\text { Unstandardized } \\
\text { Coefficompetitive intelligence } \\
\text { Network nts }\end{array}$} & \multirow{2}{*}{$\begin{array}{c}\text { Standardized } \\
\text { Coefficompetitive } \\
\text { intelligence } \\
\text { Network nts } \\
\text { Beta }\end{array}$} & \multirow[t]{2}{*}{$\mathrm{t}$} & \multirow[t]{2}{*}{ Sig. } \\
\hline & & $\mathrm{B}$ & Std. Error & & & \\
\hline \multirow[t]{2}{*}{1} & (Constant) & 1.663 & .322 & & 1.881 & .000 \\
\hline & $\begin{array}{l}\text { Issue } \\
\text { knowledge }\end{array}$ & .588 & .019 & .592 & 1.775 & .000 \\
\hline \multirow[t]{3}{*}{2} & (Constant) & 1.524 & .214 & & 1.882 & .000 \\
\hline & $\begin{array}{l}\text { Issue } \\
\text { knowledge }\end{array}$ & .591 & .046 & .595 & 1.638 & .000 \\
\hline & $\begin{array}{l}\text { Competitive } \\
\text { Intelligence } \\
\text { Network }\end{array}$ & .644 & .077 & .649 & 1.523 & .000 \\
\hline
\end{tabular}

Table (10), demonstrates a hierarchal multiple regression analysis to investigate fourth research hypothesis which stated that competitive intelligence mediates Issue knowledge and Business performance. Concerning model (1) the direct relationship between Issue knowledge and Business performance, the value of $\mathrm{B}=.588$, the value of Beta $=.592$ with $\mathrm{P}$-value $=.000$ this indicated that there is a significant and positive relationship between Issue knowledge and Business performance. As for model (2) which applied multiple regression analysis to find both Issue knowledge as independent factor and Competitive intelligence as a mediator factor with Business performance as dependent factor, the findings showed that the value of $\mathrm{B}=.591$, the value of Beta $=$ .595 with P-value .001 as indirect relationship between Issue knowledge and Business performance, on the other hand the value of $B=.644$, the value of Beta $=.649$ with $\mathrm{P}$-value .000 as mediation between Competitive intelligence and Business performance. The findings proved that there is a positive and significant direct and indirect relationship between Issue knowledge and Business performance, moreover Competitive intelligence has a positive and significant mediating role between Issue knowledge and Business performance.

Table 11: Sobel Test

\begin{tabular}{|c|c|c|c|c|c|}
\hline & Input: & & Test statistic: & Std. Error: & $p$-value: \\
\hline$a$ & .591 & Sobel test: & 7.00930741 & 0.0542998 & 0.002 \\
\hline$b$ & .644 & Aroian test: & 6.9944425 & 0.0544152 & 0.003 \\
\hline$s_{\mathrm{a}}$ & .046 & Goodman test: & 7.02426751 & 0.05418416 & 0.002 \\
\hline & .077 & Reset all & \multicolumn{3}{|c|}{ Calculate } \\
\hline
\end{tabular}

P-value is significant at level 0.005 
Table (11), illustrates the findings of Sobel test to find the mediation analysis, the result demonstrates the direct relationship between Issue knowledge and Business performance, P-value $=.002$ this indicated that there is a significant and positive direct relationship between Issue knowledge and Business performance. Furthermore, P-value is .003 as indirect relationship between Issue knowledge and Business performance. Moreover, the results proved that there is a positive and significant direct and indirect relationship between Issue knowledge and Business performance, moreover Competitive intelligence has a positive and significant mediating role between Issue knowledge and Business performance.

H5: Competitive intelligence mediates promotion effort and Business performance.

Table 12: Hierarchal Multiple Regression

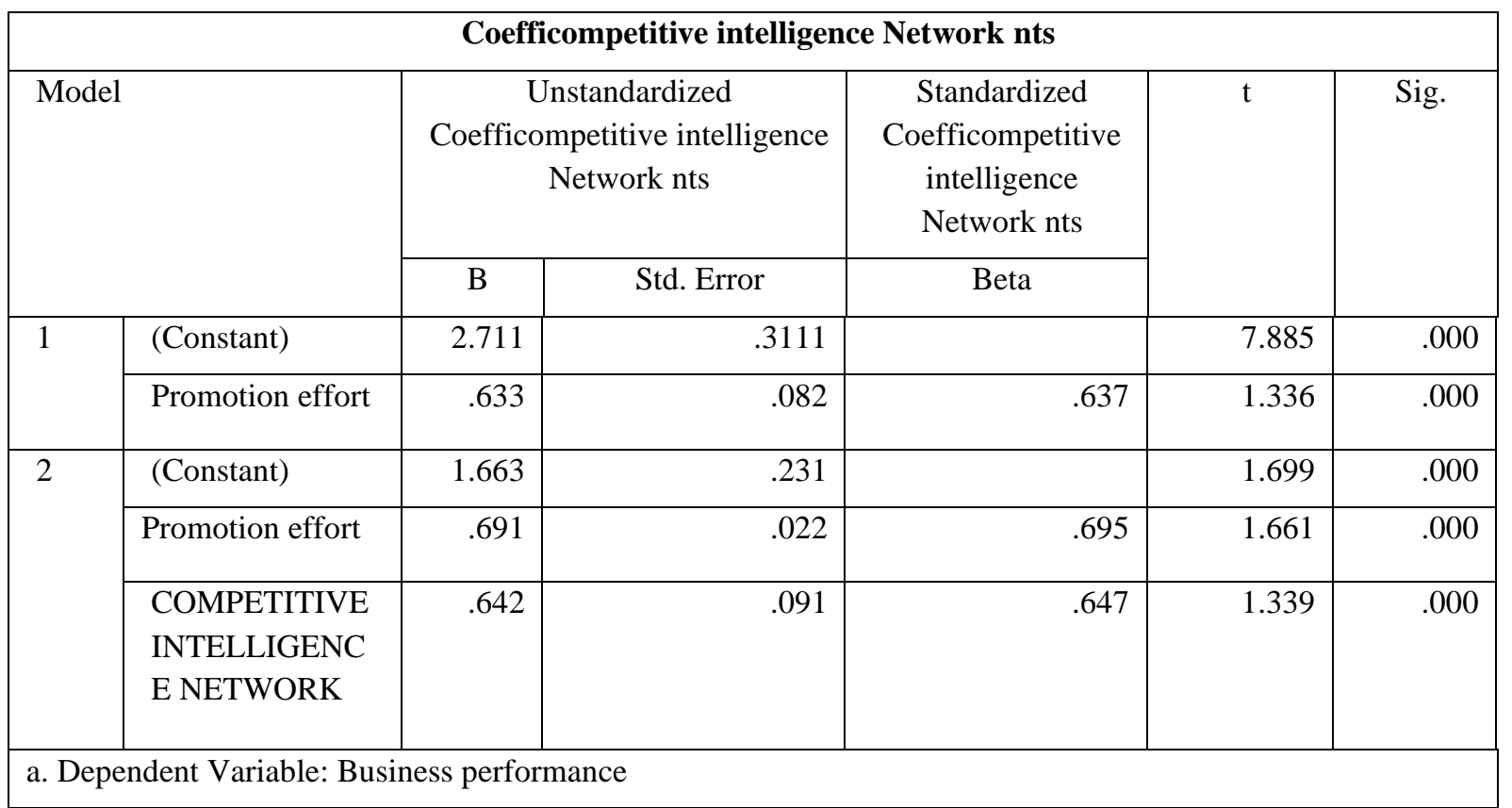

Table (12), demonstrates a hierarchal multiple regression analysis to investigate fifth research hypothesis which stated that Competitive intelligence mediates promotion effort and Business performance. Concerning model (1) the direct relationship between Issue knowledges and Business performance, the value of $\mathrm{B}=.633$, the value of Beta $=.637$ with $\mathrm{P}$-value $=.000$ this indicated that there is a significant and positive relationship between promotion effort and Business performance. As for model (2) which applied multiple regression analysis to find both promotion effort as independent factor and Competitive intelligence as a mediator factor with Business performance as dependent factor, the findings showed that the value of $\mathrm{B}=.691$, the value of $\mathrm{Beta}=$ .695 with P-value .001 as indirect relationship between promotion effort and Business performance, on the other hand the value of $\mathrm{B}=.642$, the value of Beta $=.647$ with $\mathrm{P}$-value .000 as mediation between Competitive intelligence and Business performance. The findings proved that there is a positive and significant direct and indirect relationship between promotion effort and Business performance, moreover competitive intelligence has a positive and significant mediating role between promotion effort and business performance.

Table 13: Sobel Test

\begin{tabular}{|c|c|c|c|c|c|}
\hline & Input: & & Test statistic: & Std. Error: & $p$-value: \\
\hline$a$ & .691 & Sobel test: & 6.88344068 & 0.06444771 & 0.000 \\
\hline$b$ & .642 & Aroian test: & 6.88012193 & 0.0644788 & 0.002 \\
\hline$s_{\mathrm{a}}$ & .022 & Goodman test: & 6.88676424 & 0.06441661 & 0.002 \\
\hline$s_{\mathrm{b}}$ & .091 & Reset all & \multicolumn{3}{|c|}{ Calculate } \\
\hline
\end{tabular}

P-value is significant at level 0.005 
Table (13), illustrates the findings of Sobel test to find the mediation analysis, the result demonstrates the direct relationship between promotion effort and business performance, $\mathrm{P}$-value $=.000$ this indicated that there is a significant and positive direct relationship between promotion effort and Business performance. Furthermore, P-value is .002 as indirect relationship between promotion effort and Business performance. Moreover, the results proved that there is a positive and significant direct and indirect relationship between promotion effort and business performance, moreover competitive intelligence has a positive and significant mediating role between promotion effort and Business performance.

\section{CONCLUSIONS}

The competitive intelligence diagnosis and clarification of the outcomes, according to a high-level view of respondents, have an effect on marketing strategy decisions in Erbil's five-star small and medium enterprises. The degree attained by looking ahead and seeing the highest level, which, in the long run, provides potential marketing strategy systems and diagnoses additional opportunities before other small and medium businesses would catch up, seemed to be too large in the results. These close findings support the presence of a high stage. It is possible to comprehend effective small and medium company approaches in terms of opportunity diagnosis. The descriptive research showed a strong willingness to persuade employees of small and medium-sized businesses to believe in future vision and the ability to predict the future, which aids my ability to make sound business decisions. This finding supports a high level of foresight, insight, and strategy in small and medium businesses. According to the study, higher-level thought methodology was achieved, as well as systems that react to small and medium business management's eagerness to devote time to gather information from various sources. The findings of the investigation found that small and medium-sized business owners set aside time to collect data from various sources. The findings revealed a high degree of potential foresight. Small and medium businesses pursue marketing knowledge for strategic decisions, as well as the implementation of concrete methods in small and medium business voluntary community quota requirement material, making marketing strategy decisions easier to absorb and use. The skill manager will look at the patterns and factors for high-level performance in small and medium businesses using the high-level research findings. The findings showed a high level of motivation, with this metric indicating a willingness to pay workers to carry out small and medium firm visions and perceptions, as well as a higher level of motivation in other fields. As a business intelligence component, the findings revealed a high degree of innovation, indicating a willingness to provide creative ISSN: 2456-7620 solutions to small and medium-sized businesses' marketing issues, as well as a never-ending quest for new ways to offer small and medium-sized businesses' services. The marketing campaign choices available to small and medium-sized company management, as well as forecasting the future and providing service to small and medium-sized businesses, yielded high-level findings.

To investigate the role of competitive intelligence in determining market performance at small and medium businesses in Iraq's Kurdistan region, the researchers used hierarchal multiple regression and the Sobel test. However, the researchers measured the direct impact on market efficiency at small and medium businesses using five competitive intelligence dimensions (extensiveness network, third-party strategy, homophily, issue awareness, and promotion effort). Furthermore, the researchers used competitive intelligence as a mediator to assess its impact on business success, allowing the study to explore the indirect role of competitive intelligence.

As for the first research hypothesis, the results show a direct relationship between extensiveness network and business performance, with a P-value of.000 indicating a substantial and optimistic direct relationship between extensiveness network and business performance. Furthermore, the indirect relationship between extensiveness network and business success has a P-value of.000. Furthermore, the findings revealed a positive and significant direct and indirect relationship between extensiveness network and business performance, as well as a positive and significant mediating function for competitive intelligence between extensiveness network and business performance. In terms of the second research hypothesis, the results show a direct link between third-party technique and business performance, with a $\mathrm{P}$ value of.000 indicating that there is an important and optimistic link between third-party technique and business performance. Furthermore, the indirect relationship between third-party methodology and business results has a P-value of.001. Furthermore, the findings revealed that third-party technique and business performance have a positive and meaningful direct and indirect relationship. Competitive intelligence plays a constructive and significant role in mediating the relationship between third-party technology and business success. In terms of the third research hypothesis, the results show a direct link between change assessment and business performance, with a P-value of.000 indicating that there is an important and optimistic link between change assessment and business performance. Furthermore, the indirect relationship between change appraisal and business results has a P-value of.000. Furthermore, the findings revealed that change assessment and business performance have a positive and meaningful direct and indirect relationship. Between Homophily and business success, 
competitive intelligence plays a constructive and important mediating role. In terms of the fourth research hypothesis, the results show a direct relationship between Issue knowledge and Business performance, with a P-value of.002 indicating a strong and optimistic direct relationship between Issue knowledge and Business performance. Furthermore, the indirect relationship between Issue information and Business success has a P-value of.003. Furthermore, the findings revealed a positive and significant direct and indirect relationship between Issue awareness and Business performance, as well as a positive and significant mediating function for Competitive intelligence between Issue knowledge and Business performance. The outcome of the fifth research hypothesis shows a direct relationship between promotion effort and business performance, with a P-value of.000 indicating an important and optimistic direct relationship between promotion effort and business performance. Furthermore, the indirect relationship between promotion effort and business success has a P-value of.002. Furthermore, the findings revealed a positive and significant direct and indirect relationship between promotion effort and business performance, as well as a positive and significant mediating function for competitive intelligence between promotion effort and business performance.

\section{REFERENCES}

[1] López-Robles, J. R., Otegi-Olaso, J. R., Arcos, R., GamboaRosales, N. K., \& Gamboa-Rosales, H. (2018). Mapping the structure and evolution of JISIB: A bibliometric analysis of articles published in the Journal of Intelligence Studies in Business between 2011 and 2017. Journal of intelligence studies in business, $8(3), 1-12$

[2] Granados, O. M., \& Velez-Langs, O. E. (2018, July). Competitive intelligence in the service sector: a data visualization approach. In International Conference on Human-Computer Interaction (pp. 238-246). Springer, Cham.

[3] Koriyow, O. I., \& Karugu, L. (2018). Competitive intelligence strategies and performance of commercial banks in Garrisa County, Kenya. International Academic Journal of Human Resource and Business Administration, 3(1), 371-394.

[4] Anwar, G., \& Shukur, I. (2015). The Impact of Training and Development on Job Satisfaction: A Case Study of Private Banks in Erbil. International Journal of Social Sciences \& Educational Studies, 2(1), 65.

[5] Xuefei, F., Jian, H., \& Hongmei, Y. (2018). Research on Enterprise Competitive Technology Intelligence Based on Improved Patent Portfolio. Journal of Intelligence.

[6] Anwar, G., \& Shukur, I. (2015). Job satisfaction and employee turnover intention: A case study of private hospital in Erbil. International Journal of Social Sciences \& Educational Studies, 2(1), 73.

[7] Ali, B. J. (2021). Assessing (The impact) of advertisement on customer decision making: Evidence from an educational institution. Ali, BJ (2021). Assessing (The impact) of advertisement on customer decision making: Evidence from an educational institution. Afak for Science Journal, 6(01), 267280.

[8] Gatibu, J., \& Kilika, J. (2017). Competitive intelligence practices and performance of Equity Bank in Kenya. International Academic Journal of Human Resource and Business Administration, 2(4), 219-239.

[9] Anwar, G., \& Shukur, I. (2015). the impact of recruitment and selection on job satisfaction: Evidence from private school in Erbil. International Journal of Social Sciences \& Educational Studies, 1(3), 4-13.

[10] Demir, A., Maroof, L., Khan, N. U. S., \& Ali, B. J. (2020). The role of E-service quality in shaping online meeting platforms: a case study from higher education sector. Journal of Applied Research in Higher Education, 1-28

[11] Anwar, G., \& Abd Zebari, B. (2015). The Relationship between Employee Engagement and Corporate Social Responsibility: A Case Study of Car Dealership in Erbil, Kurdistan. International Journal of Social Sciences \& Educational Studies, 2(2), 45.

[12] Kumar, V., Saboo, A. R., Agarwal, A., \& Kumar, B. (2020). Generating competitive intelligence with limited information: a case of the multimedia industry. Production and Operations Management, 29(1), 192-213.

[13] Anwar, G., \& Surarchith, N. K. (2015). Factors Affecting Shoppers' Behavior in Erbil, Kurdistan-Iraq. International Journal of Social Sciences \& Educational Studies, 1(4), 10.

[14] Andavar, V., \& Ali, B. (2020). Rainwater for Water Scarcity Management: An Experience of Woldia University (Ethiopia). ANDAVAR, V., ALI, BJ, \& ALI, SA (2020). Rainwater for Water Scarcity Management: An Experience of Woldia University (Ethiopia). The Journal of Business Economics and Environmental Studies, 10(4), 29-34.

[15] Anwar, G., \& Shukur, I. (2015). The Impact of Service Quality Dimensions on Students' Satisfaction. International Journal of Social Sciences \& Educational Studies, 76.

[16] Muñoz-Cañavate, A., \& Hípola, P. (2017). Information resources for competitive intelligence: An approach to the information available on the European Union's websites. Journal of Business \& Finance Librarianship, 22(1), 32-45.

[17] Anwar, K. (2017). Analyzing The Conceptual Model Of Service Quality And Its Relationship With Guests'satisfaction: A Study Of Hotels In Erbil. The International Journal of Accounting and Business Society, 25(2), 1-16.

[18] Ali, B. J. (2021). Impact of consumer animosity, boycott participation, boycott motivation, and product judgment on purchase readiness or aversion of Kurdish consumers in Iraq. Journal of Consumer Affairs.

[19] Mehl, E., \& Le Bon, J. (2019). Social Listening: Adapting Customer and Competitive Intelligence to the Digital Era: An Abstract. In Academy of Marketing Science Annual Conference (pp. 243-244). Springer, Cham.

[20] Anwar, K. (2016). Comparison between cost leadership and differentiation strategy in agricultural businesses. Custos E Agronegocio on Line, 12(2), 212-231. 
[21] Abdullah, M. S., Toycan, M., \& Anwar, K. (2017). The cost readiness of implementing e-learning. Custos E Agronegocio On Line, 13(2), 156-175.

[22] Anwar, K., \& Balcioglu, H. (2016). The relationship between transformational leadership characteristics and effectiveness: A case study of construction companies in Erbil. International Journal of Science Technology and Management, 5(2), 250256.

[23] Caseiro, N., \& Coelho, A. (2019). The influence of Business Intelligence capacity, network learning and innovativeness on startups performance. Journal of Innovation \& Knowledge, 4(3), 139-145.

[24] Anwar, K. (2017). The Role of Effective Leadership in Crisis Management: Study of Private Companies in Kurdistan. Qalaai Zanist Scientific Journal, 2(4), 326-338.

[25] Ali, B. (2020). Impact of COVID-19 on Consumer Buying Behavior Toward Online Shopping in Iraq. Ali, BJ (2020). Impact of COVID-19 on consumer buying behavior toward online shopping in Iraq. Economic Studies Journal, 18(42), 267-280.

[26] Hameed, A. A., \& Anwar, K. (2018). Analyzing the Relationship between Intellectual Capital and Organizational Performance: A Study of Selected Private Banks in Kurdistan. International Journal of Social Sciences \& Educational Studies, 4(4), 39.

[27] Anwar, K., \& Ghafoor, C. (2017). Knowledge management and organizational performance: A study of private universities in Kurdistan. International Journal of Social Sciences \& Educational Studies, 4(2), 53.

[28] Naeini, A. B., Mosayebi, A., \& Mohajerani, N. (2019). A hybrid model of competitive advantage based on Bourdieu capital theory and competitive intelligence using fuzzy Delphi and ism-gray Dematel (study of Iranian food industry). International Review, (1-2), 21-35.

[29] Anwar, K., \& Climis, R. (2017). Analyzing the relationship between types of advertisement and customer choice: a study of retailer stores in erbil. The International Journal of Accounting and Business Society, 25(2), 43-52.

[30] Saddhono, K., Chin, J., Toding, A., Qadri, M. N., \& Wekke, I. S. (2019). Competitive intelligence: Systematic collection and analysis of information. Journal of Critical Reviews, 6(5), 155159.

[31] Anwar, K. (2017). Factors affecting stock exchange investment in kurdistan. The International Journal of Accounting and Business Society, 25(1), 32-37.

[32] Espinet, E. O., \& Alsina, M. G. (2017). Networks of scientific collaboration in competitive intelligence studies. Theorie, Semantik und Organisation von Wissen, 13, 423.

[33] Anwar, K., \& Qadir, G. H. (2017). A Study of the Relationship between Work Engagement and Job Satisfaction in Private Companies in Kurdistan. International Journal of Advanced Engineering, Management and Science, 3(12), 239944.

[34] Alia, B. J. Consumer attitudes towards healthy and organic food in the Kurdistan region of Iraq. Journal of Growing Science, 1-8.

[35] Anwar, K. (2017). Leading Construction Project Teams: The Effectiveness of Transformational Leadership in Dynamic Work Environments in Kurdistan. International Journal of
Advanced Engineering, Management and Science, 3(10), 239925.

[36] Fanbing, S. U. O. (2017). Probe into Competitive Intelligence Research of Domestic Enterprises Based on Social Network Analysis. Journal of Library and Information Science, 12.

[37] Anwar, K., \& Louis, R. (2017). Factors Affecting Students' Anxiety in Language Learning: A Study of Private Universities in Erbil, Kurdistan. International Journal of Social Sciences \& Educational Studies, 4(3), 160.

[38] Ali, B., \& Anwar, G. (2021). The balanced scorecard's evolution as a strategic mechanism at banking sectors. International Journal of English Literature and Social Sciences, 6(1); 471-478 https://dx.doi.org/10.22161/ijels.61.63

[39] Zhiyin, Y., \& Jiakun, H. (2017, July). The Application of Network Link Analysis in Enterprise Competitive Intelligence. In 2017 7th International Conference on Social Network, Communication and Education (SNCE 2017) (pp. 856-860). Atlantis Press.

[40] Abdullah, N., \& Anwar, G. (2021). An Empirical Analysis of Natural Gas as an Alternative Fuel for Internal Transportation. International Journal of English Literature and Social Sciences, 6(1) ; 479-485 https://dx.doi.org/10.22161/ijels.61.64

[41] Ali, B., \& Anwar, G. (2021). The Effect of Marketing Culture Aspects of SMEs Care on Marketing Creativity. International Journal of English Literature and Social Sciences, 6(2); 171182 https://dx.doi.org/10.22161/ijels.62.25

[42] Itani, O. S., Agnihotri, R., \& Dingus, R. (2017). Social media use in B2b sales and its impact on competitive intelligence collection and adaptive selling: Examining the role of learning orientation as an enabler. Industrial Marketing Management, 66, 64-79.

[43] Abdullah, N., \& Anwar, G. (2021). Inspiring future entrepreneurs: The effect of experiential learning on the entrepreneurial intention at higher education. International Journal of English Literature and Social Sciences, 6(2) ; 183 194 https://dx.doi.org/10.22161/ijels.62.26

[44] Tarek, B. H., Zouhayer, M., \& Adel, G. (2019). Entrepreneurial competitive intelligence between Uppsala model and born global theories in the case of North African SMEs. Journal of the Knowledge Economy, 10(2), 734-755.

[45] Abdullah, N., \& Anwar, G. (2021). The impact of Human resource management practice on Organizational performance. International journal of Engineering, Business and $\begin{array}{llll}\text { Management } & \text { (IJEBM) } & 5(1) & ;\end{array}$ https://dx.doi.org/10.22161/ijebm.5.1.4

[46] Zhao, J., Wang, J., Fang, S., Zhang, H., Jin, P., Visvizi, A., ... \& Zhang, X. (2019). A Framework for the Competitive Intelligence Service System for Strategic Emerging Industries in China. In The New Silk Road Leads through the Arab Peninsula: Mastering Global Business and Innovation. Emerald Publishing Limited.

[47] Ali, B \& Anwar, G. (2021). Factors Influencing the Citizens' Acceptance of Electronic Government. International journal of Engineering, Business and Management (IJEBM) 5(1) ; 48-60 https://dx.doi.org/10.22161/ijebm.5.1.5

[48] Shaitura, S. V., Ordov, K. V., Lesnichaya, I. G., Romanova, Y. D., \& Khachaturova, S. S. (2018). Services and mechanisms of competitive intelligence on the internet. Espacios, 39(45), 24. 
[49] Abdullah, N., \& Anwar, G. (2021). Global Financial Outlook during the COVID-19 Pandemic: The role of effective leadership styles on Financial outlook. International journal of Engineering, Business and Management (IJEBM) 5(2) ; 8-20 https://dx.doi.org/10.22161/ijebm.5.2.2

[50] Ali, B \& Anwar, G. (2021). An Empirical Study of Employees' Motivation and its Influence Job Satisfaction. International journal of Engineering, Business and Management (IJEBM) 5(2) ; 21-30 : https://dx.doi.org/10.22161/ijebm.5.2.3

[51] López-Robles, J. R., Otegi-Olaso, J. R., Porto-Gómez, I., Gamboa-Rosales, H., \& Gamboa-Rosales, N. K. (2020). Understanding the intellectual structure and evolution of Competitive Intelligence: A bibliometric analysis from 1984 to 2017. Technology analysis \& strategic management, 32(5), 604-619. 